\title{
EXTRUSION, DEBINDING AND SINTERING OF A COMMERCIAL PURE TITANIUM INK FOR ROBOCASTING
}

\author{
Adelia KASHIMBETOVA, Serhii TKACHENKO, Karel SLÁMEČKA, Michaela REMEŠOVÁ, \\ Lenka KLAKURKOVÁ, Zina PAVLOUŠKOVÁ, Ladislav ČELKO, Edgar B. MONTUFAR \\ CEITEC - Brno University of Technology, Brno, Czech Republic, EU, kashimbetova@vutbr.cz, \\ eb.montufar@ceitec.vutbr.cz
}

https://doi.org/10.37904/metal.2021.4263

\begin{abstract}
Among additive manufacturing technologies, robocasting emerges as a versatile and an affordable method for processing metallic materials. However, the success and competitiveness of robocasting depend on the development of easy-to-process metallic inks that do not generate residues after debinding and production of high purity metallic parts. The additive manufacturing of titanium is in particular attractive and challenging. Titanium is a high-performance material with high specific mechanical strength, high fracture toughness, low elastic modulus, and high corrosion resistance with important applications in aerospace, marine, medical, alimentary, energy, recreational, and chemical industries. It is difficult to process titanium due to its high reactivity with oxygen and other elements that leads to the formation of oxides and brittle inclusions that impair the mechanical performance. The aim of this study is to understand the extrusion behaviour of a titanium ink and the debinding at different temperatures to obtain carbide- and oxide-free commercially pure titanium structures by robocasting. The results show that the ink meets all rheological requirements for robocasting allowing the fabrication of a variety of different titanium structures with a maximal unsupported span of $2 \mathrm{~mm}$. Furthermore, the optimization of the debinding process avoided the thermal oxidation of titanium while maximised the elimination of the binder, showing superior efficiency than other binders studied previously. The microstructure and chemical analysis of the sintered samples confirmed the chemical and crystalline purity of the material.
\end{abstract}

Keywords: Additive manufacturing, robocasting, titanium, debinding, sintering

\section{INTRODUCTION}

Additive manufacturing technologies allow superior control of the structure and, consequently, of the properties of a broad range of materials for several applications. Selective laser melting is one of the most explored additive manufacturing technologies for metals [1]. However, recently robotic assisted deposition (robocasting) emerged as an alternative for the additive manufacturing of metals [2]. Robocasting was developed originally for the fabrication of ceramic structures in Sandia National Laboratories [3]. It is based on the robotic controlled extrusion of a powder paste (i.e. ink) following a pattern predesigned in silico to fabricate a desired part layer by layer. Similar to injection moulding, the deposited part is a green body that requires high temperature sintering for consolidation. However, in contrast with injection moulding, robocasting does not require a mould, allowing the fabrication of more complex structures with near-net shape. The success of robocasting depends on several variables including a proper control of the rheological properties of the ink [4]. The ink must show pseudoplastic behaviour with a relatively high yield strength. After yield, the ink must demonstrate shear thinning behaviour to allow extrusion at low load. Then, a fast recovery of the viscous state is required to retain the shape of the deposited filaments. The high yield strength is required to allow layer-upon-layer stacking without flow or deformation of the deposited material. 
The incorporation of an organic binder is necessary in order to allow extrusion. However, the binder must be completely eliminated before sintering to avoid the reaction or contamination of the metal with the residual elements, mainly carbon. Debinding is in particular relevant for the processing of high-purity reactive metals such as commercially pure titanium. Titanium reacts with carbon at high temperature and also with the oxygen in the atmosphere, forming titanium carbides and oxides that impact the mechanical properties of the final material [5]. Moreover, since the ink is extruded trough a nozzle with an internal aperture of $250-800 \mu \mathrm{m}$, one of the most important drawbacks in robocasting is a phase separation. Thus, to achieve the required behaviour of the ink and to prevent any contamination, the selection of the organic binder is a complex and yet crucial task.

Thoroughly selected binders should result in an increase in the competitiveness of robocasting for the additive manufacturing of titanium parts. The aim of this study is to understand the extrusion behaviour of the titanium ink and the debinding of the obtained structures at different temperature performed in order to obtain carbideand oxide-free commercially pure titanium lattices. Titanium was selected due to its high specific strength and corrosion resistance allowing a broad range of applications in aerospace, marine, medical, alimentary, energy, recreational and chemical industries.

\section{MATERIALS AND METHODS}

The ink for robotic assisted deposition was prepared by mixing commercially pure spherical titanium powder (ASTM Gd1) with an organic binder soluble in water, gelatine. The ink was introduced into a cartridge of the robotic deposition device immediately after mixing.

Extrusion test was performed at room temperature in a mechanical testing machine using a tapering nozzle with an internal aperture of $610 \mu \mathrm{m}$. The test was performed at different times after mixing: 2, 15 and $20 \mathrm{~min}$, and different extrusion rates: 4, 10 and $23 \mathrm{~mm} / \mathrm{s}$. Force displacement curves, extrusion curves, were recorded and the extrusion force was determined as the load applied to maintain a constant flow of the ink in steady conditions. Images of the extruded filaments were acquired with a digital camera.

Samples of variable size were fabricated with the titanium ink using an orthogonal deposition pattern in consecutive layers with the distance between filaments from 600 to $2000 \mu \mathrm{m}$. Samples were fabricated in air at the speed of $20 \mathrm{~mm} / \mathrm{s}$. Samples were allowed to dry at room temperature for $12 \mathrm{~h}$.

Debinding experiments were performed at 250,350 and $450{ }^{\circ} \mathrm{C}$ for $12 \mathrm{~h}$ in a muffle furnace in air atmosphere. Before and after debinding the samples were analysed by scanning electron microscopy (SEM) together with energy dispersive $\mathrm{X}$-ray (EDX) analysis, $\mathrm{X}$-ray diffraction (XRD), X-ray photoelectron spectroscopy (XPS) and mass loss. Debound samples were sintered in argon atmosphere at $1300{ }^{\circ} \mathrm{C}$ for $10 \mathrm{~h}$. Sinter samples were prepared for metallographic observation following standard methods for titanium. The microstructure was observed in an optical microscope, whereas the composition was analysed by XRD and EDX before etching.

\section{RESULTS AND DISCUSION}

Figure 1 shows the extrusion curves. The curves show at the beginning a fast increment of force followed by a small plateau. The increase in the force is related to the overcome of the yield strength needed to extrude the ink through the aperture of the cartridge, whereas the plateau corresponds to the flow of the ink progressively filling the nozzle. Then, when the ink reaches the exit of the nozzle, a second and more important rise in the force is observed, as the yield strength is higher due to the smaller aperture of the nozzle. Afterwards, the ink is extruded at constant force, the extrusion force, until the cartridge is emptied and force rises due to the compression of the extrusion ram. 

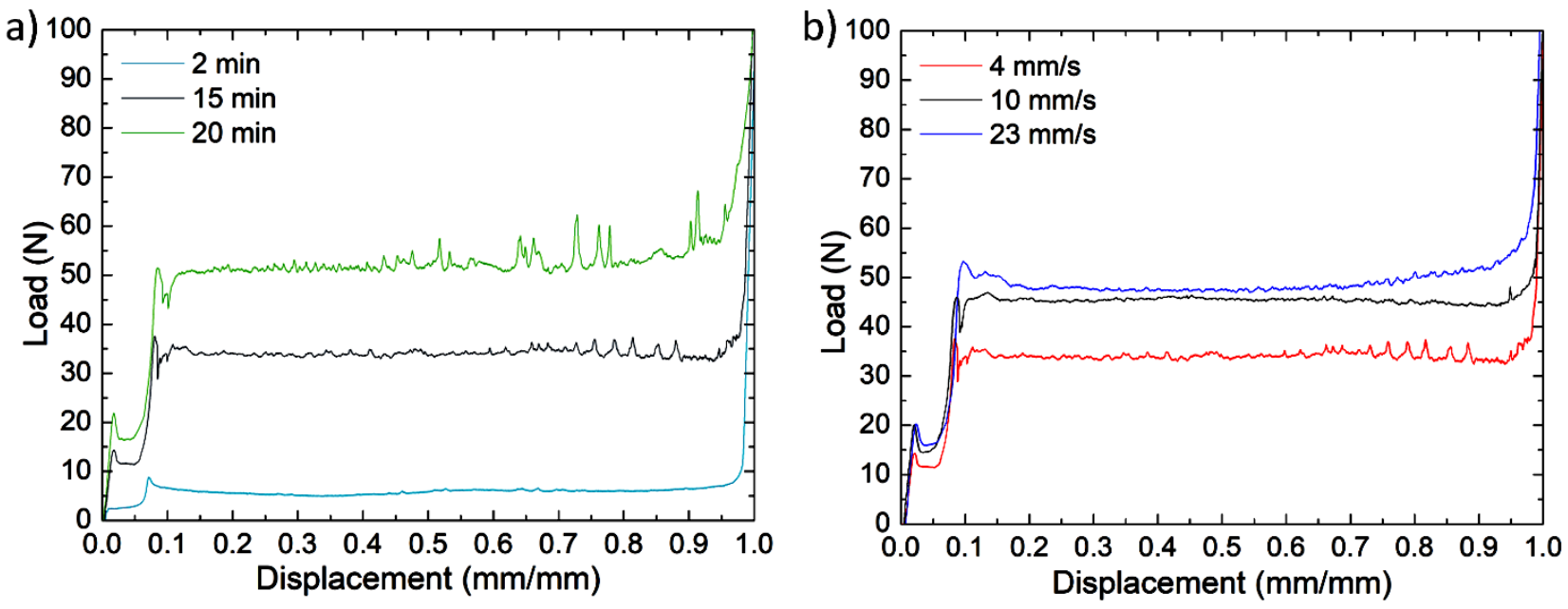

Figure 1 Force - displacement curves record during extrusion experiments: a) at constant extrusion rate of 4 $\mathrm{mm} / \mathrm{s}$; b) after $15 \mathrm{~min}$ of mixing at different extrusion rates. Displacement is presented as the fraction of the length of the cartridge

It was clear that the extrusion force increased with the time elapsed after mixing (Figure 1a). The rise in the extrusion force is explained by the rise in the viscosity of the ink due to the molecular restructuration of the binder, involving hydrogen and ionic bonds. In fact, the images in Figure $\mathbf{2}$ show that the ink extruded shortly after mixing has a low viscosity with a liquid-like behaviour, i.e. the extruded filaments fused immediately at contact by surface tension. After 15 and 20 min of mixing, the extrusion produced continuous and stable filaments that retained the shape and stack to form random hillocks that reach a height between 20 to $30 \mathrm{~mm}$ before collapsing by their own weight. No other difference than higher extrusion force was observed between extrusion at 15 and 20 min after mixing.
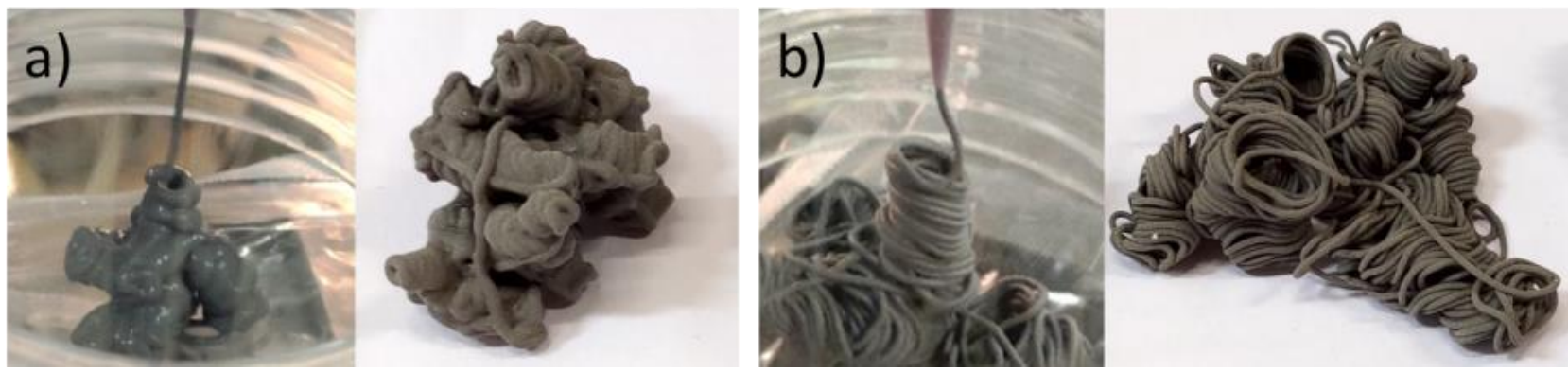

Figure 2 Representative images of the extruded ink after a) 2 and b) 15 min of mixing

Figure $1 \mathrm{~b}$ represents the effect of the extrusion rate after $15 \mathrm{~min}$ of mixing. The extrusion force increases with the increment of the extrusion rate in the range between 30 and $50 \mathrm{~N}$. This range fits very well within the working capabilities of the robotic deposition device allowing deposition at low speed for better resolution of edges and high speed for fast object fabrication. Figure $\mathbf{3}$ demonstrates the diversity of shapes and sizes that can be fabricated by robocasting using the titanium ink. The maximum unsupported span deposited in this work was $2 \mathrm{~mm}$, but it is possible that bigger cantilevers may be achieved with good resolution. Possible applications for the titanium structures include filtration, catalysis, tissue engineering scaffolds, bone grafts, armours and others. The current limitation is the volume of the object that can be fabricated, restricted to 5 $\mathrm{cm}^{3}$ by the size of the cartridge. 


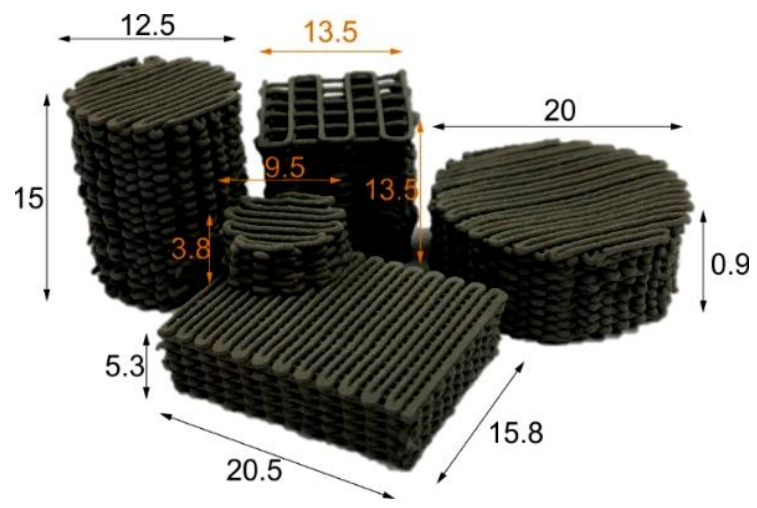

Figure 3 Examples of the different titanium structures that can be fabricated by robocasting (all dimensions are in $\mathrm{mm}$ ). Samples before debinding

Figure 4 shows the titanium powder before and after debinding at different temperature. The presence of the residual binder was not evident visually in all samples at low magnification (Figures $\mathbf{4 a}, \mathbf{b}, \mathbf{d}, \mathbf{e}$ ). However, observation at higher magnification revealed that only debinding at $250{ }^{\circ} \mathrm{C}$ did not result in the complete removal of the binder, since the powder had a small quantity of randomly distributed aggregates of titanium particles surrounded presumably by the remaining binder (Figure 4c).
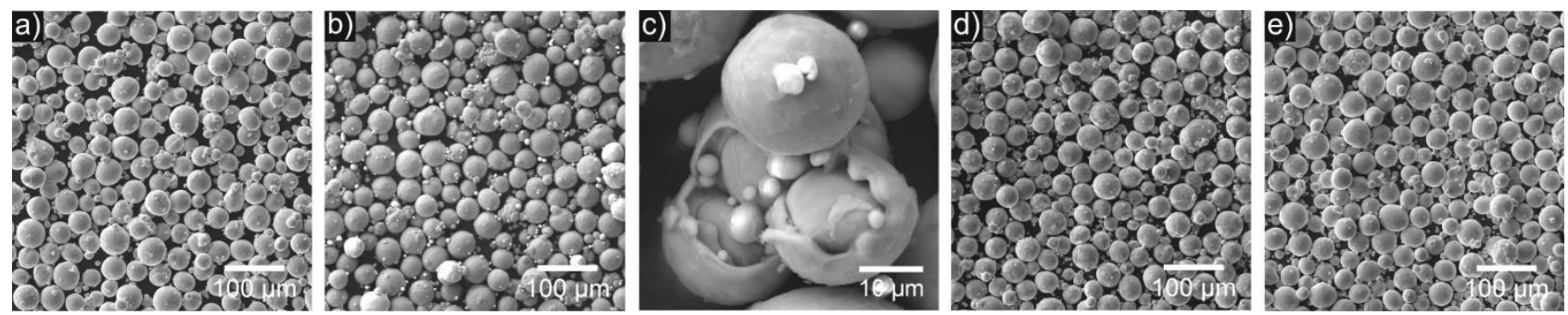

Figure 4 SEM images of a) the initial titanium powder, and the powders after debinding at b) and c) $250{ }^{\circ} \mathrm{C}$,

d) $350^{\circ} \mathrm{C}$, e) $450^{\circ} \mathrm{C}$

The EDX analysis showed that titanium content decreased with debinding without evident differences among different temperature (Figure 5a). In contrast, highest content of carbon was found in the sample treated at $250^{\circ} \mathrm{C}$ confirming the incompleteness of the binder removal observed earlier by SEM. Higher temperature led to a lower content of carbon reaching a level similar to the one of the initial powder. Despite the fact that debinding at $450{ }^{\circ} \mathrm{C}$ resulted in the complete elimination of the organic binder, thermal oxidation was observed on these samples. This was confirmed not only by the highest content of oxygen reflected in EDX results but also by a clear change in colour from grey to navy blue (Figure $5 \mathbf{b}$ ), what did not happen to samples debound at 250 and $350{ }^{\circ} \mathrm{C}$.
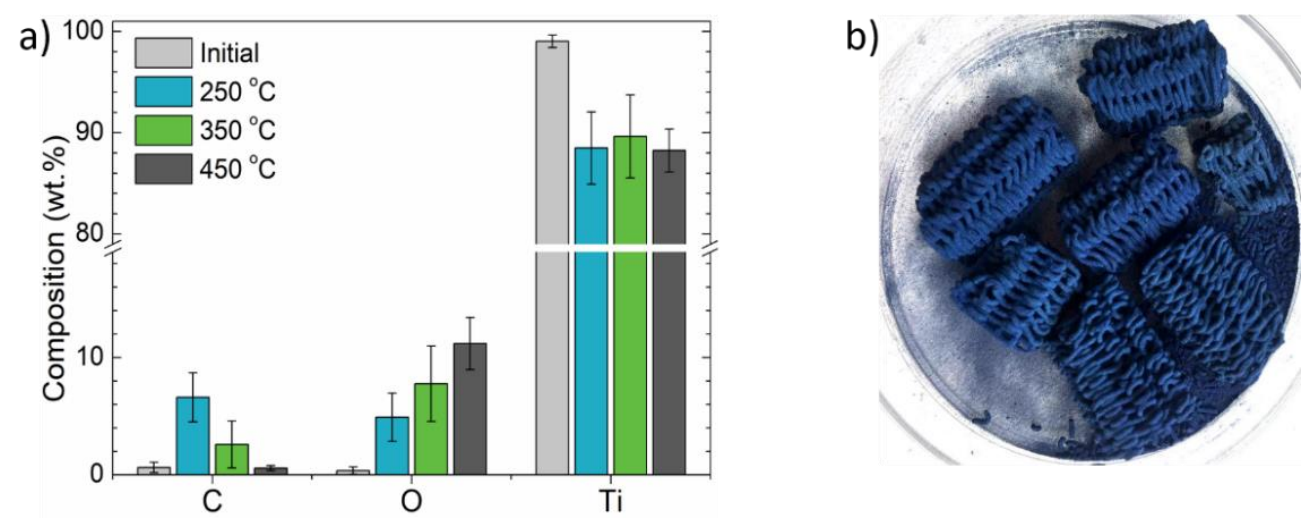

Figure 5 Debinding of samples at different temperature, a) results of the EDX analysis and b) representative image of the samples debound at $450{ }^{\circ} \mathrm{C}$ 
XPS spectra show oxygen, titanium and carbon as of three main elements at the surface level in all samples (Figure 6). Additionally, samples debound at 250 and $350{ }^{\circ} \mathrm{C}$ had $\mathrm{N} 1 \mathrm{~s}$ peak. Quantitative XPS analysis showed that samples debound at 250 and $350{ }^{\circ} \mathrm{C}$ had about 15 at.\% of nitrogen, 30 at.\% less of oxygen and 30 at. \% more of carbon in comparison with the initial powder which did not give signal of nitrogen and contained 50 and 30 at.\% of oxygen and carbon, respectively. Therefore, it is clear that higher nitrogen and carbon content is the result of the incomplete removal of the organic binder, changing the composition of the titanium dioxide layer to a more nitride and carbide chemical nature.

Samples debound at $450^{\circ} \mathrm{C}$ showed equivalent XPS spectrum than the raw powder (Figure 6), with equivalent chemical composition of the oxide layer. However, as observed in Figure $\mathbf{5 b}$, the change of colour of the samples suggests that the oxide layer formed at $450{ }^{\circ} \mathrm{C}$ is significantly thicker than the layer generated at room temperature. These results indicate that the binder produces chemical modifications of the surface of the powder during debinding, however, the changes below $450^{\circ} \mathrm{C}$ are not representative of the bulk of the material.

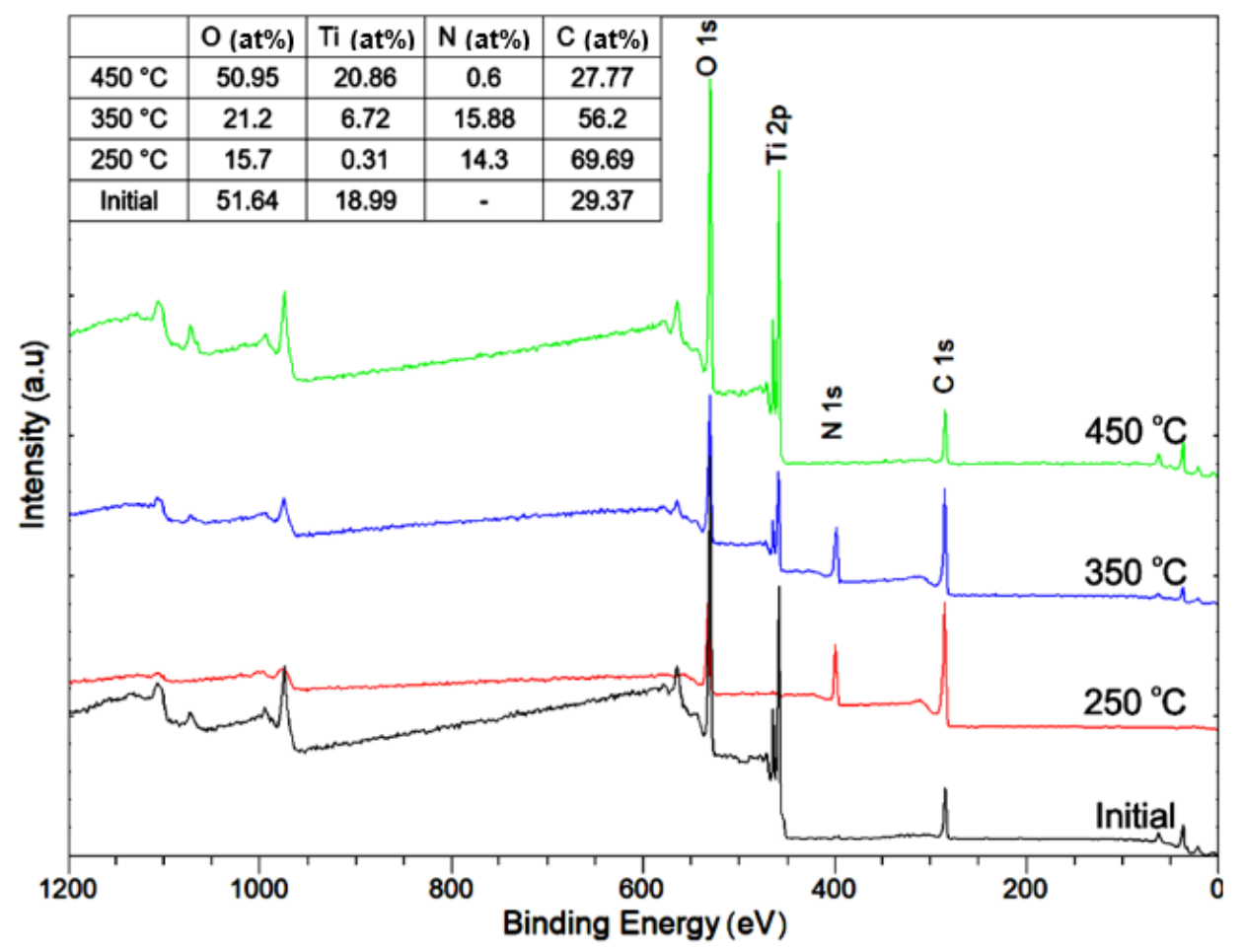

Figure 6 Surface elemental analysis by XPS before and after debinding. The elemental chemical composition is in atomic percentage

The phase purity of the powder was confirmed by XRD with Cu-Ka wavelength in reflection mode. The analysis did not show any difference in phase composition of the samples treated at different temperature (Figure 7). All the peaks in the diffraction patterns were identified as hexagonal titanium. Therefore, the volume fraction of any superficial second phase is below the detection limit of $\mathrm{XRD}$, even the thick oxide layer formed at $450{ }^{\circ} \mathrm{C}$.

In summary, the results indicate that the optimal debinding temperature is $350{ }^{\circ} \mathrm{C}$, as this temperature maximises the removal of carbon and nitrogen, while minimises the thermal oxidation of titanium. The experimental mass loss after debinding at this temperature was $90 \%$ of the theoretical expected. The efficiency in the debinding was superior to that observed previously when chitosan was used as binder [6] and similar to that observed with Pluronic $[7,8]$. 


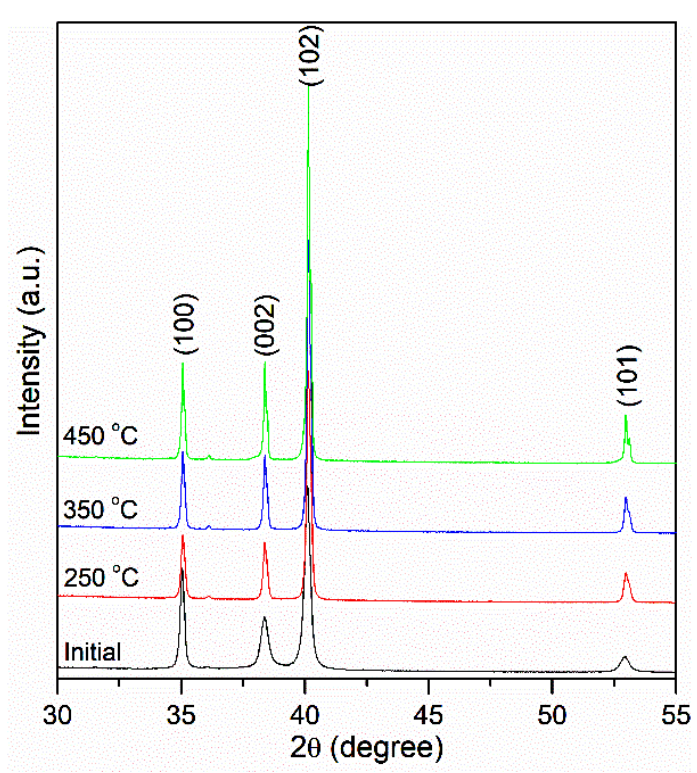

Figure 7 XRD patterns before and after debinding

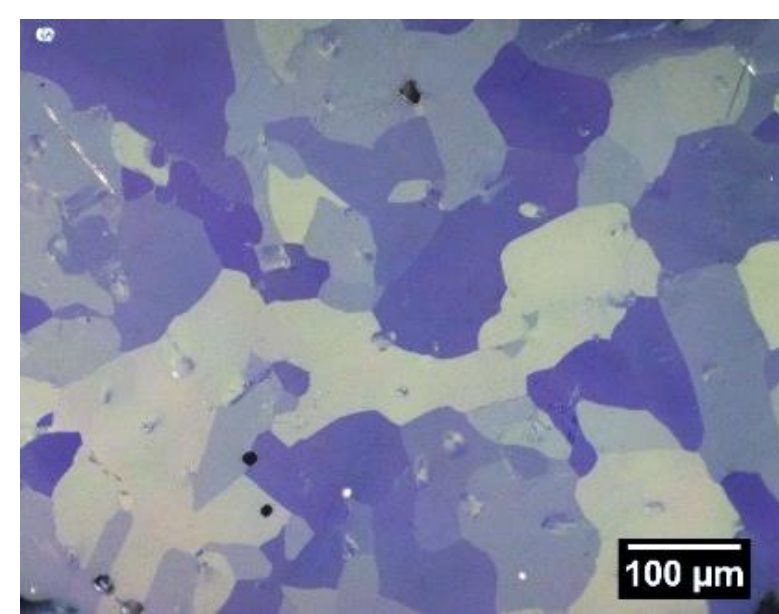

Figure 8 Microstructure of the sintered titanium at $1300{ }^{\circ} \mathrm{C}$ for $10 \mathrm{~h}$

Figure 8 shows the microstructure of the sinter sample, which exhibited equiaxed alpha titanium grains with size of $67 \mu \mathrm{m}$ in average, few small pores and no evidences of carbide or oxide inclusions, as proof of titanium purity after sintering. This is a significant step forward respect the use of Pluronic as binder, which generates carbide inclusions [7]. Chemical purity was confirmed by XRD and EDX analysis, showing hexagonal titanium as the only crystalline phase and $95.5 \mathrm{wt} \%$ of titanium, $3.7 \mathrm{wt} \%$ of oxygen, $0.8 \mathrm{wt} \%$ of carbon and no signal of nitrogen in the metallographic cross-section of the sinter sample.

\section{CONCLUSION}

The titanium ink studied meets the requirements for robocasting, allowing the fabrication of a variety of different titanium structures, with maximum unsupported span of $2 \mathrm{~mm}$. Efficient debinding was also achieved with minimal thermal oxidation of the titanium powder and very small residual fractions of carbon and nitrogen that did not generate inclusions or secondary phases in the microstructure of the sintered titanium samples. Robocasting is envisaged as cheaper additive manufacturing technology than selective laser melting for titanium, and the limits in the fabrication of complex structures, dimensional accuracy and mechanical performance deserve to be studied in future.

\section{ACKNOWLEDGEMENTS}

This work was supported by the Czech Science Foundation (grant 19-22662S). A.K. acknowledges the Brno Ph.D. Talent scholarship founded by the Brno City Municipality and the project CEITEC VUT/FAST-J-21-7305. Part of the work was carried out on the devices purchased by CEITEC Nano Research Infrastructure supported by MEYS-CR (LM2018110).

\section{REFERENCES}

[1] GUNASEKARAN, J., SEVVEL, P., SOLOMON I.J. Metallic materials fabrication by selective laser melting: A review. Materials Today: Proceedings. 2021, vol. 37, no. 2, pp. 252-256.

[2] JAKUS, A.E., TAYLOR, S.L., GEISENDORFER, N.R., DUNAND, D.C., SHAH, R.N. Metallic architectures from 3d-printed powder-based liquid inks. Advanced Functional Materials. 2015, vol. 25, no. 45, pp. 6985-6995. 
[3] CESARANO III, J., CALVERT, P.D. Free forming objects with low-binder slurry. US6027326 A. 1997.

[4] MINAS, C., CARNELLI, D., TERVOORT, E., STUDART, A.R. 3D printing of emulsions and foams into hierarchical porous ceramics. Advanced Materials. 2016, vol. 28, no. 45, pp. 9993-9999.

[5] OGDEN, H.R, JAFFEE, R.I. The effects of carbon, oxygen, and nitrogen on the mechanical properties of titanium and titanium alloys. [online]. United States: N. p., 1955. Available from: https://doi.org/10.2172/4370612.

[6] XU, C., WU, Q., L'ESPÉRANCE, G., LEBEL, L. L., THERRIAULT, D. Environment-friendly and reusable ink for 3D printing of metallic structures. Materials \& Design. 2018, vol. 160, pp. 262-269.

[7] MONTUFAR, E. B., TKACHENKO, S., CASAS-LUNA, M., ŠKARVADA, P., SLÁMEČKA, K., DIAZ-DE-LATORRE, S., KOUTNÝ, D., PALOUŠEK, D., KOLEDOVÁ, D. Z., HERNÁNDEZ-TAPIA, L.G., ZIKMUND, T., ČELKO, L., KAISER, J. Benchmarking of additive manufacturing technologies for commercial-pure-titanium bonetissue-engineering scaffolds: processing-microstructure-property relationship. Additive Manufacturing. 2020, vol. 36, p. 101516.

[8] VIDAL, E., TORRES, D., GUILLEM-MARTI, J., SCIONTI, G., MANERO, J. M., GINEBRA, M. P., RODRÍGUEZ, D., RUPÉREZ. Titanium scaffolds by direct ink writing: fabrication and functionalization to guide osteoblast behavior. Metals. 2020, vol. 10, no. 9, p. 1156. 